\title{
Outdoor weathering performance parameters of exterior wood coating systems on tropical hardwood substrates
}

De Windt Imke ${ }^{1 *}$, Van den Bulcke Jan ${ }^{1}$, Wuijtens Inge ${ }^{2}$, Coppens Hugo ${ }^{2}$, Van Acker Joris ${ }^{1}$

${ }^{1}$ Laboratory of Wood Technology, Department of Forest and Water Management, Faculty of Bioscience Engineering, Ghent University, Ghent

${ }^{2}$ Centre Technique de l'Industrie du Bois/Technisch Centrum der HoutNijverheid, Allée Hof ter Vleestdreef 3, Brussels

*corresponding author: Imke.DeWindt@UGent.be

Laboratory of Wood Technology

Department of Forest and Water Management

Faculty of Bioscience Engineering

Coupure Links 653, 9000 Ghent, Belgium

Tel: +32(0)9 2646123

Fax: +32(0)9 2646233

www.woodlab.be

\section{Abstract}

Wood coating research almost exclusively focuses on softwood as substrate despite the fact that coatings applied on tropical hardwoods show a different weathering behaviour. The objective of this study was to quantify the impact of wood substrate and coating type on the weathering behaviour of finished wooden joinery in outdoor exposure using a set of statistical methods. Therefore, a broad range of white opaque paints and mid-oak semitransparent stains were used. The coatings were industrially applied on window frames made of frequently used commercial tropical hardwood species. The general appearance of the wood/coating systems was assessed visually using a rating scale that takes into account the anatomical characteristics of hardwood. A minimum required exposure time for evaluation of 2.5 years outdoor weathering for joinery in vertical position and facing south-west was determined. At 30 months best performances were recorded for waterborne alkyd primers with an acrylic topcoat when dry coating film was sufficiently thick. The dry layer thickness also affected the impact of the hiding power on the performance of the wood/coating system. Within hardwood species the degradation rate of coatings on species with a fine texture was the lowest. The significant influence of the substrate's texture on the weathering behaviour of coated hardwood stressed the need to evaluate the wood/coating system in total.

Keywords: exterior wood coating, natural weathering, dry layer thickness, tropical hardwood 


\section{Introduction}

Exterior wooden joinery is an efficient thermal insulator and its technical and aesthetical service life can be prolonged considerably when maintained properly. Its easiness to repair also contributes to the environmental friendly image and long service life. Furthermore, wood as a renewable resource is less harmful to the environment than most alternatives (Petersen and Solberg 2005; Salazar and Sowlati, 2008). Despite these advantages the market share for windows and exterior doors is still larger for PVC and aluminum than for wood (VFF 2011). Exterior wooden joinery has to meet stringent requirements such as high dimensional stability, high durability and weathering resistance. In order to prolong the service life of a wooden component the protective function of a coating is beneficial.

However, a longer service life demands a coating that should retain its physical and protective properties in addition to its aesthetical function,. These properties are partially affected by the wood substrate. Dimensional stability, surface roughness, wood anatomy and wood density of the substrate influence the wood-coating interface (Richter et al. 1995; Williams et al. 2000). Earlier studies have focused on treated or untreated softwood as substrate for coatings (Creemers et al. 2002, Nejad and Cooper 2011, Grüll et al. 2013). Few studies incorporate tropical hardwoods (Roux M.L. et al. 1988; Boxall et al. 1992; Van den Bulcke et al. 2006). Tropical hardwood species have typical characteristics that will affect the outdoor performance of a coating differently, even if we account for the fact that softwood is a demanding substrate.

Chemical composition of the paint is a key factor as well. Nowadays more complex coating systems are available on the market such as low VOC waterborne paints instead of solventborne coatings. As a result no applicable theory about the relation between physical paint properties and typical paint failure is established yet (Custódio and Eusébio 2006; de Meijer and Nienhuis 2009). An important factor in understanding the mechanism of coating failure during weathering is the resistance against internal, hygroscopic and thermal stress (Perera 1996). As waterborne coatings are more permeable to moisture due to their dispersed nature (Nicholson 1993; Overbeek 2010) they are exposed to higher stress levels at the woodcoating interface. An increased water permeability causes a swelling of the coating (de Meijer and Nienhuis 2009) followed by more frequent dimensional changes of the wood substrate. Coating systems showing insufficient extensibility will crack. Moreover stress decreases coating adhesion thus provoking blistering and flaking (Perera 1996).

The objective of this study was to quantify the impact of wood substrate and coating type on the weathering behaviour of finished wooden joinery in outdoor exposure using a set of 
statistical methods. Therefore, the performance of the surfaces of vertically exposed window frames covering a broad range of modern, factory applied coating systems on several tropical hardwood species was visually assessed.

\section{Materials and methods}

\section{Materials}

A broad range of industrial coatings was chosen. Paints (opaque white systems) as well as stains (semi-transparent mid-oak systems) were used in the test set-up. Eight commercial hardwood species often used in Belgium for exterior joinery were selected depending on the degree of difficulty to finish and/or the sensitivity to fungal disfigurement: afzelia (Afzelia bipindensis), merbau (Intsia palembanica), padauk (Pterocarpus soyauxii), sipo (Entandrophragma utile), sapele (Entandrophragma cylindricum), meranti (Shorea spp.), moabi (Baillonella toxisperma) and movingui (Distemonanthus benthamianus).

The coatings were professionally applied by brushing or spraying on wooden window frames measuring $1 \times 1 \mathrm{~m}^{2}$. This was done during the standard industrial production process according to best practice of the manufacturers. 51 different wood/coating systems, consisting of the combination of wood substrate and coating, were included in this research. For each wood/coating system three replicates were produced resulting in 153 full scale window frames without glazing. Table 1 gives an overview of the test materials.

\section{Outdoor exposure}

The windows were exposed outdoors, positioned vertically facing south west at three different locations to cover the Belgian temperate maritime climate: Bertrix (Walloon region Ardennes plateau), Ypres (Flanders - coastal polders) and Ghent (Flanders - urban area) (Fig. 1). This resulted in a set of 51 frames exposed to natural weathering at each site. The coated surfaces of the two jambs (vertical parts) and lintel (upper horizontal part) were assessed separately and were considered as replicates, resulting in three replicates per site for each of the $51 \mathrm{wood} /$ coating systems.. 
Table 1 Description of the test materials exposed at each exposure site

\begin{tabular}{|c|c|c|c|c|c|c|}
\hline system & wood_species & hiding_power & primer & topcoat & coating_type & replicates \\
\hline Af_O-Salk-Wacr & afzelia & opaque & $\begin{array}{l}\text { solventborne } \\
\text { alkyd }\end{array}$ & $\begin{array}{l}\text { waterborne } \\
\text { acrylic }\end{array}$ & Other & 2 \\
\hline Af_O-Walk-Wacr & afzelia & opaque & $\begin{array}{l}\text { waterborne } \\
\text { alkyd }\end{array}$ & $\begin{array}{l}\text { waterborne } \\
\text { acrylic }\end{array}$ & Walk-Wacr & 3 \\
\hline Af_O-Wacr & afzelia & opaque & $\begin{array}{l}\text { waterborne } \\
\text { acrylic }\end{array}$ & $\begin{array}{l}\text { waterborne } \\
\text { acrylic }\end{array}$ & Wacr & 2 \\
\hline Af_O-Salk & afzelia & opaque & $\begin{array}{l}\text { solventborne } \\
\text { alkyd }\end{array}$ & $\begin{array}{l}\text { solventborne } \\
\text { alkyd }\end{array}$ & Other & 1 \\
\hline Af_T-Wacr & afzelia & $\begin{array}{l}\text { semi- } \\
\text { transparent }\end{array}$ & $\begin{array}{l}\text { waterborne } \\
\text { acrylic }\end{array}$ & $\begin{array}{l}\text { waterborne } \\
\text { acrylic }\end{array}$ & Wacr & 4 \\
\hline Af_T-Wacr-Salk & afzelia & $\begin{array}{l}\text { semi- } \\
\text { transparent }\end{array}$ & $\begin{array}{l}\text { waterborne } \\
\text { acrylic }\end{array}$ & $\begin{array}{l}\text { solventborne } \\
\text { alkyd }\end{array}$ & Other & 1 \\
\hline Mb_O-Walk-Wacr & merbau & opaque & $\begin{array}{l}\text { waterborne } \\
\text { alkyd }\end{array}$ & $\begin{array}{l}\text { waterborne } \\
\text { acrylic }\end{array}$ & Walk-Wacr & 1 \\
\hline Mb_T-Walk-Wacr & merbau & $\begin{array}{l}\text { semi- } \\
\text { transparent }\end{array}$ & $\begin{array}{l}\text { waterborne } \\
\text { alkyd }\end{array}$ & $\begin{array}{l}\text { waterborne } \\
\text { acrylic }\end{array}$ & Walk-Wacr & 1 \\
\hline Pa_O-Wacr & padauk & opaque & $\begin{array}{l}\text { waterborne } \\
\text { acrylic }\end{array}$ & $\begin{array}{l}\text { waterborne } \\
\text { acrylic }\end{array}$ & Wacr & 2 \\
\hline Pa_O-Wacr/PU & padauk & opaque & $\begin{array}{l}\text { waterborne } \\
\text { acrylic/PU }\end{array}$ & $\begin{array}{l}\text { waterborne } \\
\text { acrylic/PU }\end{array}$ & Other & 1 \\
\hline Pa_T-Whyb & padauk & $\begin{array}{l}\text { semi- } \\
\text { transparent }\end{array}$ & $\begin{array}{l}\text { waterborne } \\
\text { hybrid }\end{array}$ & $\begin{array}{l}\text { waterborne } \\
\text { hybrid }\end{array}$ & Other & 1 \\
\hline Pa_T-Wacr & padauk & $\begin{array}{l}\text { semi- } \\
\text { transparent }\end{array}$ & $\begin{array}{l}\text { waterborne } \\
\text { acrylic }\end{array}$ & $\begin{array}{l}\text { waterborne } \\
\text { acrylic }\end{array}$ & Wacr & 2 \\
\hline Mt_O-Wacr/PU & meranti & opaque & $\begin{array}{l}\text { waterborne } \\
\text { acrylic/PU }\end{array}$ & $\begin{array}{l}\text { waterborne } \\
\text { acrylic/PU }\end{array}$ & Other & 1 \\
\hline Mt_O-Wacr & meranti & opaque & $\begin{array}{l}\text { waterborne } \\
\text { acrylic }\end{array}$ & $\begin{array}{l}\text { waterborne } \\
\text { acrylic }\end{array}$ & Wacr & 3 \\
\hline Mt_O-Walk-Wacr & meranti & opaque & $\begin{array}{l}\text { waterborne } \\
\text { alkyd }\end{array}$ & $\begin{array}{l}\text { waterborne } \\
\text { acrylic }\end{array}$ & Walk-Wacr & 2 \\
\hline Mt_T-Whyb-Wacr & meranti & $\begin{array}{l}\text { semi- } \\
\text { transparent }\end{array}$ & $\begin{array}{l}\text { waterborne } \\
\text { hybrid }\end{array}$ & $\begin{array}{l}\text { waterborne } \\
\text { acrylic }\end{array}$ & Other & 1 \\
\hline Sa_O-Wacr & sapele & opaque & $\begin{array}{l}\text { waterborne } \\
\text { acrylic }\end{array}$ & $\begin{array}{l}\text { waterborne } \\
\text { acrylic }\end{array}$ & Wacr & 3 \\
\hline Si_O-Wacr & sipo & opaque & $\begin{array}{l}\text { waterborne } \\
\text { acrylic }\end{array}$ & $\begin{array}{l}\text { waterborne } \\
\text { acrylic }\end{array}$ & Wacr & 2 \\
\hline Moa_O-Walk-Wacr & moabi & opaque & $\begin{array}{l}\text { waterborne } \\
\text { alkyd }\end{array}$ & $\begin{array}{l}\text { waterborne } \\
\text { acrylic }\end{array}$ & Walk-Wacr & 2 \\
\hline Moa_O-Wacr & moabi & opaque & $\begin{array}{l}\text { waterborne } \\
\text { acrylic }\end{array}$ & $\begin{array}{l}\text { waterborne } \\
\text { acrylic }\end{array}$ & Wacr & 3 \\
\hline Moa_T-Wacr & moabi & $\begin{array}{l}\text { semi- } \\
\text { transparent }\end{array}$ & $\begin{array}{l}\text { waterborne } \\
\text { acrylic }\end{array}$ & $\begin{array}{l}\text { waterborne } \\
\text { acrylic }\end{array}$ & Wacr & 3 \\
\hline Mov_O-Wacr & movingui & opaque & $\begin{array}{l}\text { waterborne } \\
\text { acrylic }\end{array}$ & $\begin{array}{l}\text { waterborne } \\
\text { acrylic }\end{array}$ & Wacr & 2 \\
\hline Mov_O-Salk & movingui & opaque & $\begin{array}{l}\text { solventborne } \\
\text { alkyd }\end{array}$ & $\begin{array}{l}\text { solventborne } \\
\text { alkyd }\end{array}$ & Other & 1 \\
\hline Mov_T-Whyb-Wacr & movingui & $\begin{array}{l}\text { semi- } \\
\text { transparent }\end{array}$ & $\begin{array}{l}\text { waterborne } \\
\text { hybrid }\end{array}$ & $\begin{array}{l}\text { waterborne } \\
\text { acrylic }\end{array}$ & Other & 1 \\
\hline Mov_T-Whyb & movingui & $\begin{array}{l}\text { semi- } \\
\text { transparent }\end{array}$ & $\begin{array}{l}\text { waterborne } \\
\text { hybrid }\end{array}$ & $\begin{array}{l}\text { waterborne } \\
\text { hybrid }\end{array}$ & Other & 1 \\
\hline Mov_T-Wacr & movingui & $\begin{array}{l}\text { semi- } \\
\text { transparent }\end{array}$ & $\begin{array}{l}\text { waterborne } \\
\text { acrylic }\end{array}$ & $\begin{array}{l}\text { waterborne } \\
\text { acrylic }\end{array}$ & Wacr & 4 \\
\hline Mov_T-Salk & movingui & $\begin{array}{l}\text { semi- } \\
\text { transparent }\end{array}$ & $\begin{array}{l}\text { solventborne } \\
\text { alkyd }\end{array}$ & $\begin{array}{l}\text { solventborne } \\
\text { alkyd }\end{array}$ & Other & 1 \\
\hline
\end{tabular}



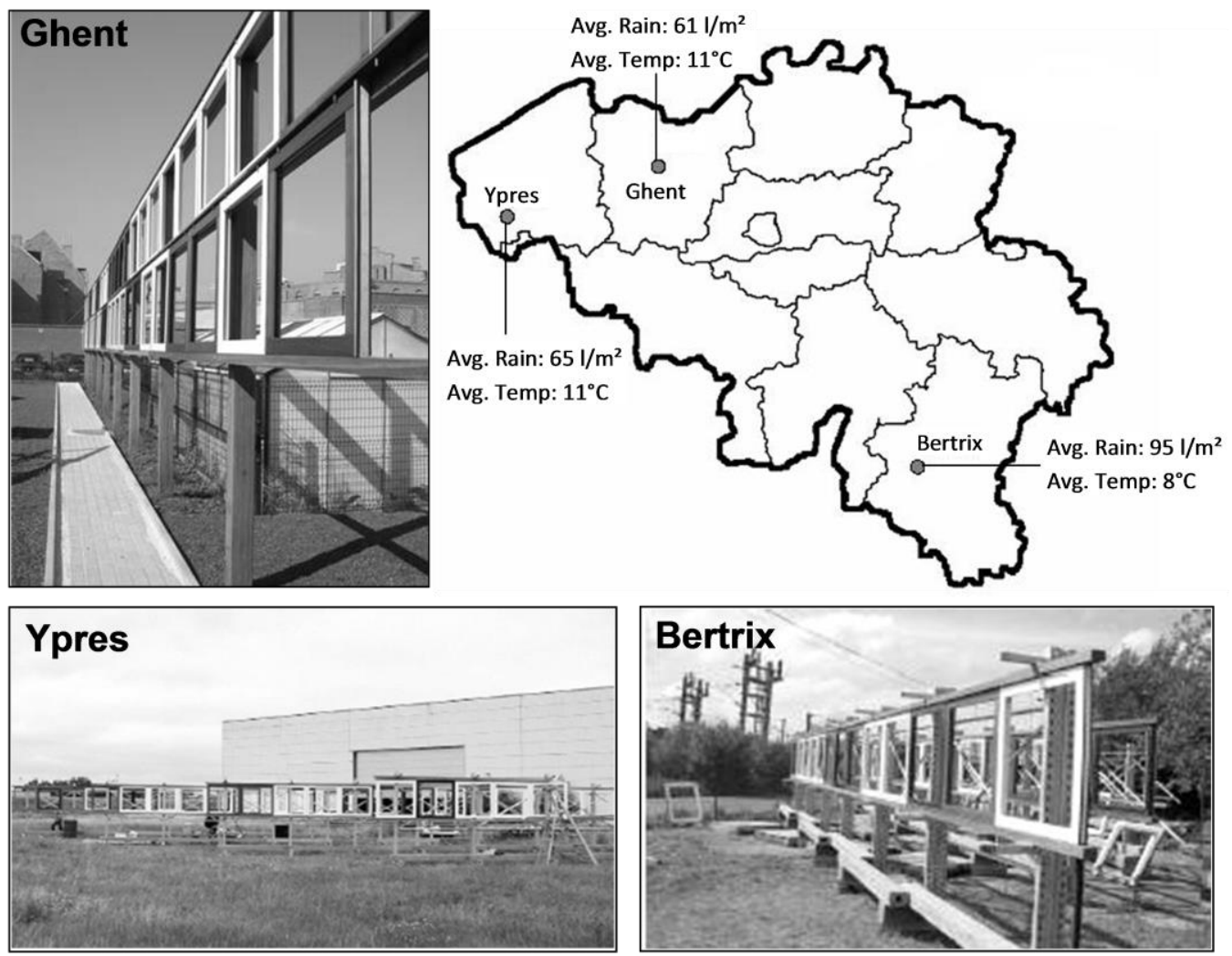

Fig. 1: Vertically exposed window frames at three different locations in Belgium with indication of the average rain fall and temperature over 5 years outdoor exposure per location

\section{Visual assessment}

All frames were assessed visually each summer and winter for a period up to five years using an adapted version of the rating scale developed in view of retreatability by Van Acker et al. (1992) (Table 2). In contrast to the prescribed evaluation methodology of EN927-3 (CEN/TC139 2006) focusing on softwood sapwood, this scale is suitable to assess the weathering of coatings on tropical hardwood as it combines different features and includes specific degradation phenomena. The rating numbers have an increment of 2 allowing intermediate ratings. The latter can be given when the degradation clearly changed in comparison to former evaluations but not yet reached the specifically described rating.

\section{Layer thickness}

The dry layer thickness of the coating was measured using confocal scanning laser microscopy (CSLM, Biorad MRC-1024) as described by Van den Bulcke et al. (2003). For each window frame under study one small cube of approximately $1 \mathrm{~cm}^{3}$ was prepared. Impregnation of the wood with safranin and smoothing of the surface was performed to improve image quality (Ryckaert et al. 2001). To measure the layer thickness of the entire 
coating for each cube six images of the cross sections of the coated surface were made.

Images were processed automatically and the mean layer thickness of the coating system was calculated.

Table 2 Visual rating scale used to evaluate the overall outdoor performance of wood/coating systems with a view to appropriate maintenance (adapted from Van Acker et al., 1992)

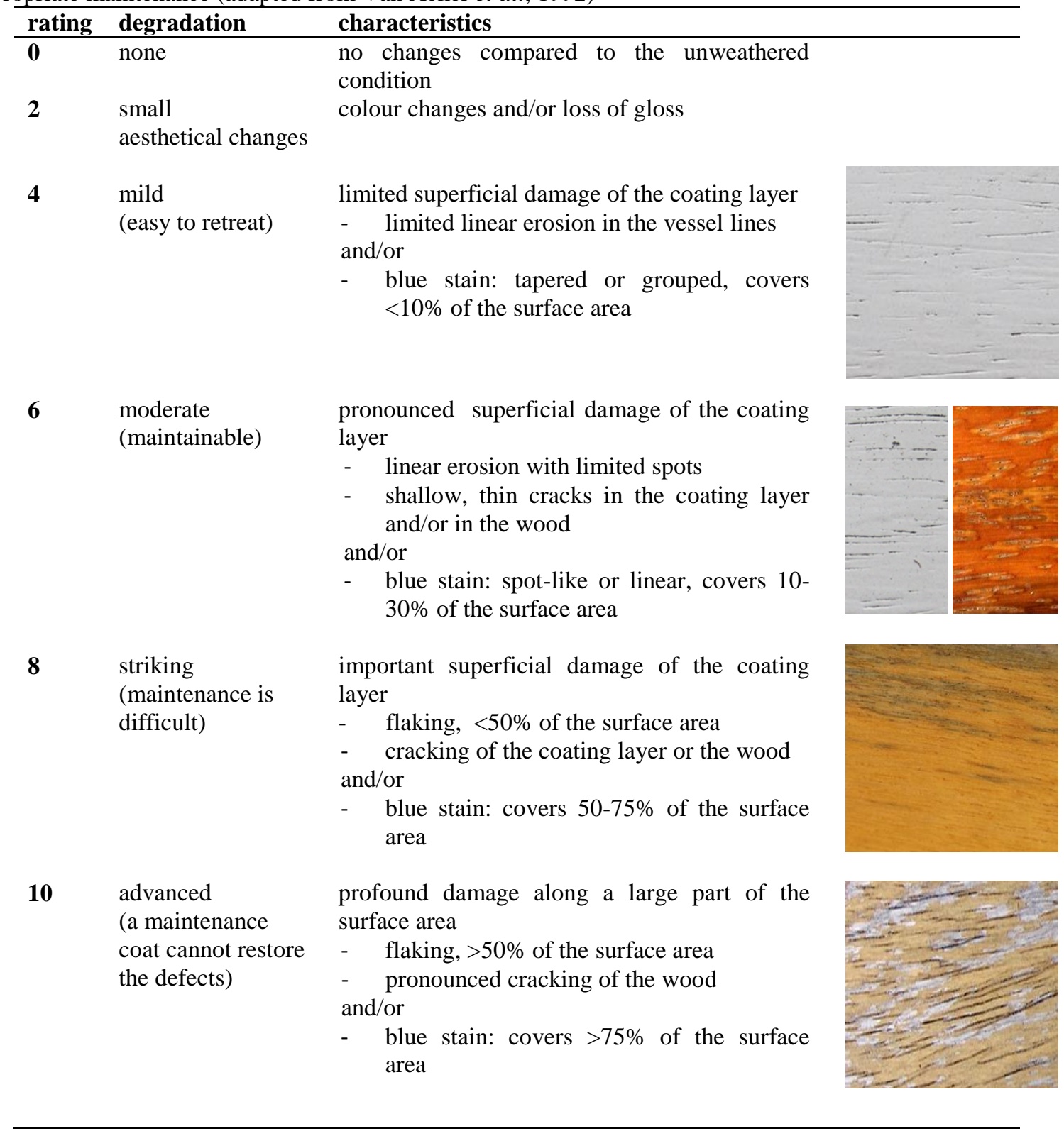

\section{Statistics}

Sequentially constrained sum-of-squares cluster analysis CONISS (Grimm 1987) was used to identify for each site major changes in degradation rate over time. Sequential zonation was further accomplished by optimal sum-of-squares zonation (Birks and Gordon 1985), using the broken-stick model proposed by Bennett (1996) to determine the optimal amount of zones. The degradation rate over time was divided in a number of statistically significant different time spans in such a way that the sum of the variances of each time span was reduced as much 
as possible relative to the total variance in the whole dataset. The time at which a distinct change in degradation rate occurred and, wood/coating systems will differentiate most was defined accordingly. The analysis was performed using ZONE version 1.2 and BSTICK version 1.0.

Visual ratings at the time of maximum differentiation, as determined with abovementioned zonation method, was used as input for Functional Data Analysis (FDA). FDA is a collection of statistical techniques associated with multivariate data analysis and allows cluster analysis using fitted functions rather than individual data points. Clustering resulted in different groups of wood/coating systems corresponding with a certain performance level. For each distinguished group the performance level was defined by using the maximum ratings of the wood/coating systems in that group. Analyses were performed in the statistical package R ( R Development Core Team 2010) for each exposure site separately.

The relation between coating characteristics, substrate and exposure site and the susceptibility of a window frame to degradation by outdoor weathering was studied using Categorical Data Analysis (CDA). The data were analysed by means of a proportional odds logistic regression analysis as the performance of coatings during weathering was assessed by means of an ordinal rating scale. This analysis contains a series of logistic regressions for dependent binary variables, with common regression parameters reflecting the proportional odds assumption. (Brant 1990). The model was determined by means of backward and forward regression. The performance classes as defined by the FDA cluster analysis were taken as possible ordinal outcome. Five predictor variables were included: substrate, coating, dry layer thickness, hiding power and exposure site. All predictor variables were made categorical with the exception of dry layer thickness which is kept as a continuous variable. Wood species were sorted into three groups of substrates: fine, medium and coarse. This classification was based on the surface texture of the wood species as described in the TROPIX $7^{\odot}$ database (CIRAD 2012). The texture of the wood represents the distinctive composition of its characteristic anatomical features taking into account their size and shape and thus defining the anatomical roughness of the wood. Three different types of coatings were distinguished 'WalkWacr', 'Wacr' and 'Other' containing respectively coating systems with a waterborne alkyd undercoat finished with an acrylic mid- and topcoat, pure acrylics and coating systems of other constitution. Classification by hiding power distinguishes opaque paints that obliterate all substrate colour and pattern, and semi-transparent stains that do not totally obscure the wood surface (EN927-1, CEN/TC139 2013). CDA was performed in the statistical package R (R Development Core Team 2010). 


\section{Results}

\section{Outdoor weathering}

This study contains the data of five years of outdoor exposure, starting from July 2004 up to July 2009.

One year outdoor exposure caused mainly aesthetical changes for both opaque paints and semi-transparent stains. When coatings were applied on padauk or afzelia, mild erosion occurred at the vessels. This was most pronounced for semi-transparent stains. A rating of 6 was given for both semi-transparent hybrid systems (T-Whyb) with dry layer thickness $<80$ $\mu \mathrm{m}$. Although this coating system performed better on movingui than on padauk there was hardly a coating film left of the thin layered systems T-Whyb after two years outdoor weathering (rating 8 and 10 respectively). In general most wood/coating systems showed limited degradation (rating $\leq 4$ ) until 24 months outdoor weathering.

After three years weathering nearly all acrylics on padauk and afzelia showed distinct cracks at the vessels stepwise progressing further along the surface. For acrylics on fine wood species such as moabi and movingui only first signs of coating degradation were noticed (rating $\leq 4)$. After four years most acrylic wood/coating systems were rated $>4$. When weathered for five years acrylic coatings on coarse substrates started to flake (rating $>6$ ) especially when semi-transparent stains were used. Acrylics on fine substrates performed slightly better $(4<$ rating $\leq 6)$. Similar results were recorded for coating types other than 'Wacr' or 'WalkWacr'. The best results were obtained when a waterborne alkyd is used as a

primer as only mild degradation was noticed after five years even for coatings on coarse wood species.

The recorded degree of coating degradation at the surface of the jambs and lintel was of similar order at all three exposure sites (Fig. $2 \mathrm{a}$ and b).

\section{Classification of wood/coating systems}

Coating degradation gradually became more pronounced during weathering. However, the rate of degradation varied in time. Using sequential zonation, three statistically significant different time spans, each with little variation in degradation rate, were defined. At the beginning of the weathering the erosion phenomena appeared in rapid succession while later on the degradation rate slowed down. For each exposure site the same three periods were distinguished as shown in Fig. $2 \mathrm{a}$ and b. 

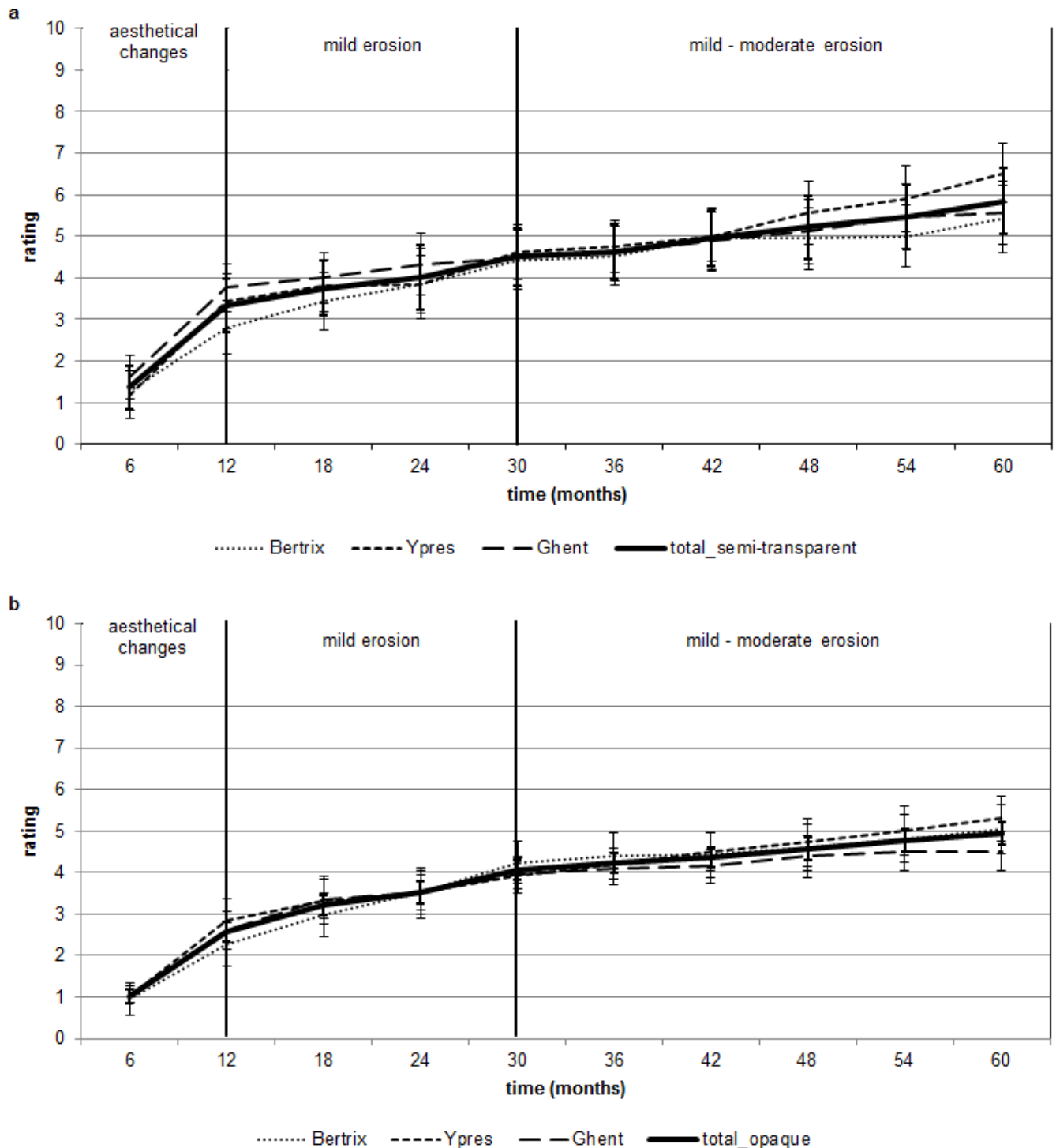

Fig. 2: Mean ratings and $95 \%$ confidence intervals per site (dotted curves) and of all sites together (full black curve) as a function of time for semitransparent (a) and opaque (b) systems

In the first phase, up to one year outdoor weathering, mainly aesthetical changes appeared. The second phase was characterized by mild degradation and ranges from nine to 30 months. In the third phase, from 30 to 60 months, the rate of degradation remained constant. Therefore, the visual ratings at 30 months were considered sufficient for weathering assessment of the wood/coating systems under study.

The performance level of all wood/coating systems was determined by means of FDA using the visual assessments up to 30 months. Three different groups were distinguished (Fig. 3). 

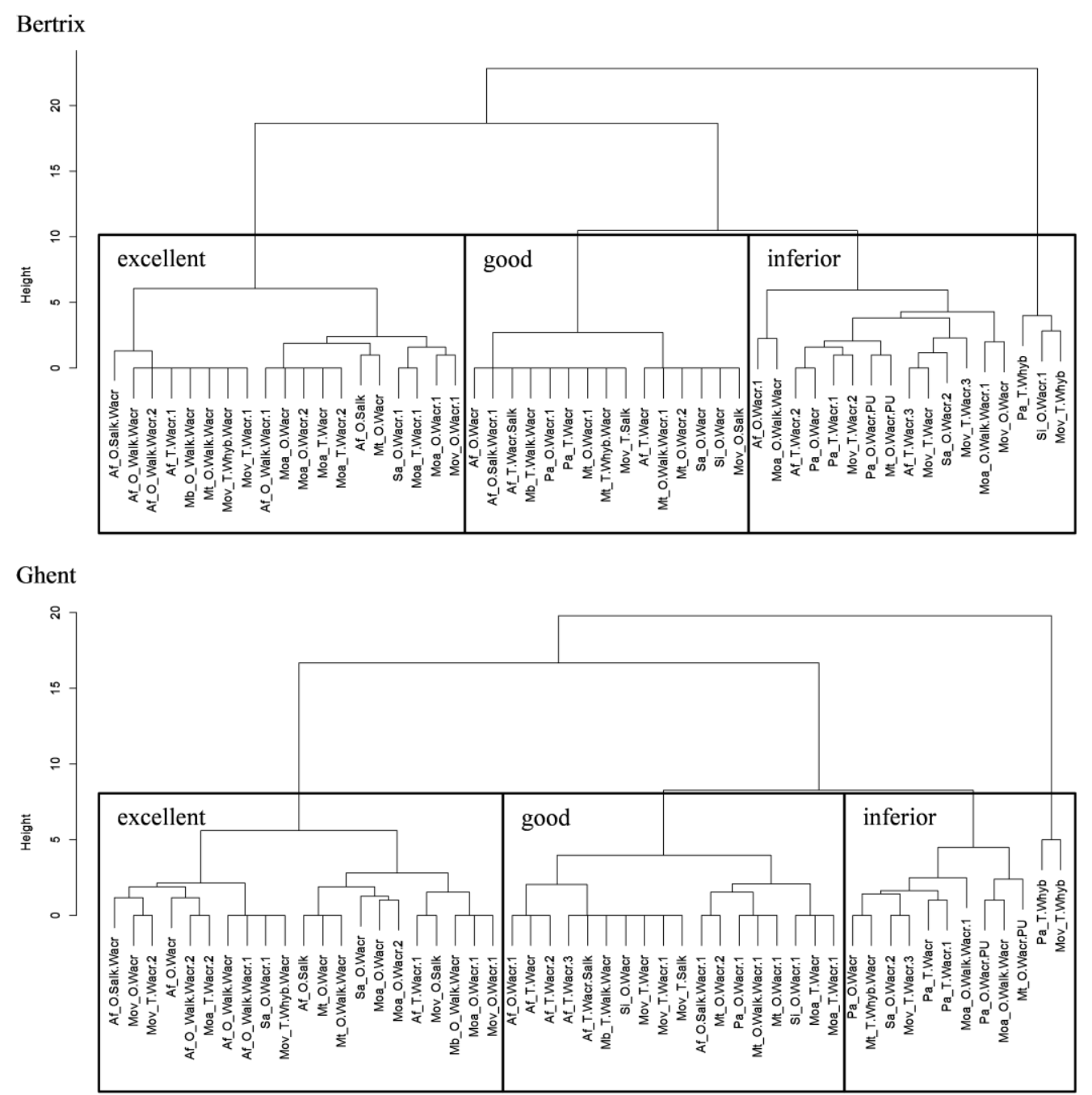

Ypres

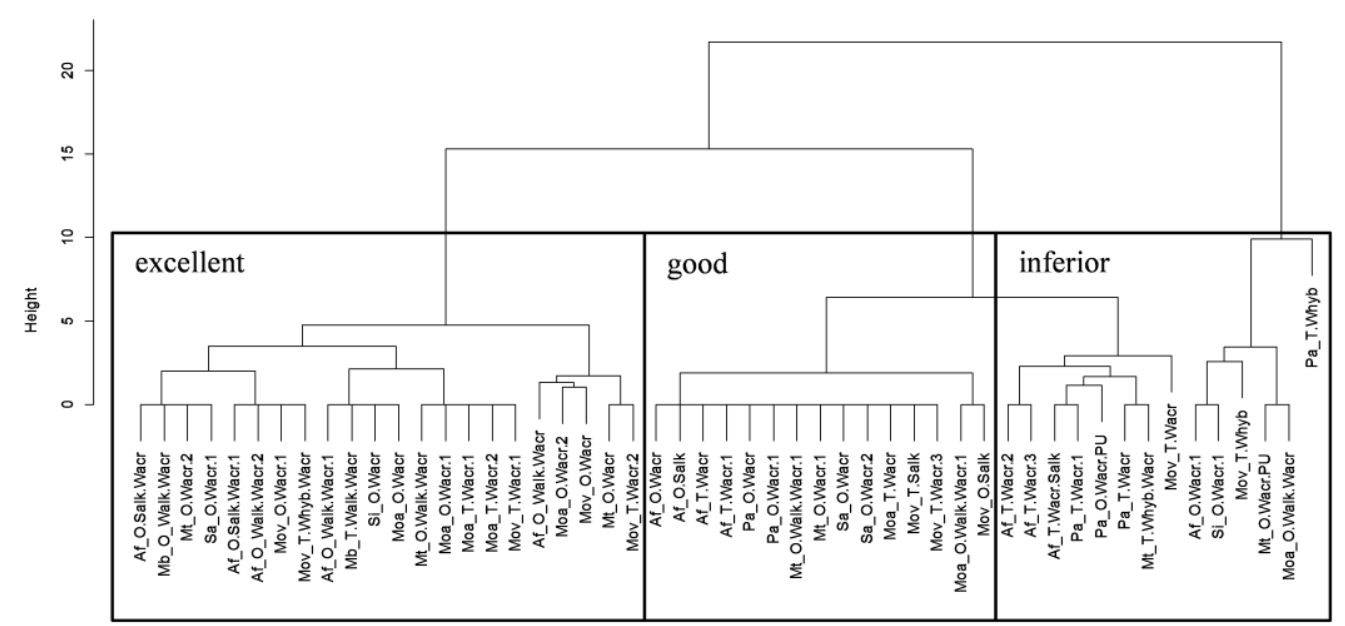

Fig. 3: Classification tree of the different wood/coating systems according to the visual rating of the surfaces of jambs and lintel at each site during 30 months outdoor weathering 
Table 3 Overview of the test materials at each site with indication of substrate texture according to CIRAD (2012), mean and standard deviation of the measured dry layer thickness and mean rating of jambs and lintel at each exposure site. Replicates are indicated by numbering $.1, .2, .3$.

\begin{tabular}{|c|c|c|c|c|c|c|}
\hline \multirow[t]{2}{*}{ system } & \multirow[t]{2}{*}{ substrate } & \multicolumn{2}{|c|}{ dry_layer thickness $(\mu \mathrm{m})$} & \multicolumn{3}{|c|}{ visual rating after 30 months weathering } \\
\hline & & mean & stdev & Bertrix & Ypres & Ghent \\
\hline Af_O-Salk-Wacr & coarse & 115.5 & 11.6 & 2 & 2 & 3 \\
\hline Af_O-Salk-Wacr.1 & coarse & 57.3 & 9.8 & 4 & 3 & 4 \\
\hline Af_O-Wacr & coarse & 95.0 & 5.5 & 4 & 4 & 4 \\
\hline Af_O-Wacr.1 & coarse & 173.9 & 12.4 & 6 & 6 & 4 \\
\hline Af_O-Salk & coarse & 92.3 & 4.2 & 4 & 4 & 3 \\
\hline Af_O_Walk-Wacr & coarse & 109.6 & 4.0 & 3 & 3 & 3 \\
\hline Af_O_Walk-Wacr.1 & coarse & 134.4 & 3.5 & 3 & 3 & 3 \\
\hline Af_O_Walk-Wacr.2 & coarse & 131.1 & 18.3 & 3 & 3 & 3 \\
\hline Af_T-Wacr & coarse & 93.7 & 9.2 & 4 & 4 & 4 \\
\hline Af_T-Wacr.1 & coarse & 72.2 & 7.2 & 3 & 4 & 3 \\
\hline Af_T-Wacr.2 & coarse & 53.1 & 6.1 & 5 & 5 & 4 \\
\hline Af_T-Wacr.3 & coarse & 53.9 & 4.8 & 5 & 5 & 4 \\
\hline Af_T-Wacr-Salk & coarse & 53.4 & 3.1 & 4 & 5 & 4 \\
\hline Mb_O_Walk-Wacr & coarse & 80.5 & 8.1 & 3 & 2 & 3 \\
\hline Mb_T-Walk-Wacr & coarse & 119.7 & 8.1 & 4 & 3 & 4 \\
\hline Pa_O-Wacr & coarse & 86.5 & 10.9 & 5 & 4 & 5 \\
\hline Pa_O-Wacr.1 & coarse & 50.4 & 1.4 & 4 & 4 & 4 \\
\hline Pa_O-Wacr/PU & coarse & 62.5 & 9.6 & 5 & 5 & 6 \\
\hline Pa_T-Whyb & coarse & 58.2 & 4.4 & 10 & 9 & 10 \\
\hline Pa_T-Wacr & coarse & 59.7 & 3.5 & 4 & 6 & 5 \\
\hline Pa_T-Wacr.1 & coarse & 60.4 & 0.3 & 5 & 5 & 5 \\
\hline Mt_O-Wacr/PU & medium & 45.8 & 0.5 & 6 & 6 & 6 \\
\hline Mt_O-Wacr & medium & 46.1 & 3.6 & 3 & 3 & 3 \\
\hline Mt_O-Wacr.1 & medium & 40.9 & 2.6 & 4 & 4 & 4 \\
\hline Mt_O-Wacr.2 & medium & 178.7 & 5.0 & 4 & 2 & 4 \\
\hline Mt_O-Walk-Wacr & medium & 108.3 & 14.5 & 3 & 3 & 3 \\
\hline Mt_O-Walk-Wacr.1 & medium & 117.0 & 5.4 & 4 & 4 & 4 \\
\hline Mt_T-Whyb-Wacr & medium & 79.4 & 6.9 & 4 & 6 & 5 \\
\hline Sa_O-Wacr & fine & 105.0 & 3.5 & 4 & 4 & 3 \\
\hline Sa_O-Wacr.1 & fine & 75.9 & 6.4 & 3 & 2 & 3 \\
\hline Sa_O-Wacr.2 & fine & 67.6 & 9.8 & 5 & 4 & 5 \\
\hline Si_O-Wacr & medium & 118.8 & 14.6 & 4 & 3 & 4 \\
\hline Si_O-Wacr.1 & medium & 102.4 & 11.5 & 7 & 6 & 4 \\
\hline Moa_O-Walk-Wacr & fine & 70.8 & 4.4 & 6 & 6 & 6 \\
\hline Moa_O-Walk-Wacr.1 & fine & 57.7 & 3.7 & 6 & 4 & 6 \\
\hline Moa_O-Wacr & fine & 125.4 & 9.4 & 3 & 3 & 3 \\
\hline Moa_O-Wacr.1 & fine & 80.6 & 4.7 & 3 & 3 & 3 \\
\hline Moa_O-Wacr.2 & fine & 85.3 & 6.3 & 3 & 3 & 3 \\
\hline Moa_T-Wacr & fine & 58.6 & 5.5 & 3 & 4 & 4 \\
\hline Moa_T-Wacr.1 & fine & 125.2 & 11.5 & 3 & 3 & 4 \\
\hline Moa_T-Wacr.2 & fine & 77.7 & 2.5 & 3 & 3 & 3 \\
\hline Mov_O-Salk & medium & 166.4 & 12.5 & 4 & 4 & 3 \\
\hline Mov_O-Wacr & medium & 113.3 & 4.1 & 6 & 3 & 3 \\
\hline Mov_O-Wacr.1 & medium & 109.9 & 7.4 & 3 & 3 & 3 \\
\hline Mov_T-Whyb-Wacr & medium & 137.1 & 5.5 & 3 & 3 & 3 \\
\hline Mov_T-Whyb & medium & 32.0 & 1.3 & 8 & 8 & 8 \\
\hline Mov_T-Salk & medium & 87.9 & 7.3 & 4 & 4 & 4 \\
\hline Mov_T-Wacr & medium & 78.3 & 11.6 & 5 & 5 & 4 \\
\hline Mov_T-Wacr.1 & medium & 65.6 & 4.8 & 3 & 3 & 4 \\
\hline Mov_T-Wacr.2 & medium & 87.3 & 5.3 & 5 & 3 & 3 \\
\hline Mov_T-Wacr.3 & medium & 96.5 & 6.0 & 4 & 4 & 5 \\
\hline
\end{tabular}


A first group clusters 'excellent' systems that showed some aesthetical changes at 30 months weathering (rating < 4). This group contained over $70 \%$ opaque wood/coating systems. Half of these wood/coating systems were opaque paints consisting of an alkyd primer, either solventborne or waterborne and an acrylic mid- and topcoat on coarse textured wood species. Acrylics of this group were mainly applied on fine and medium substrates. A second group of wood/coating systems with only mild erosion of the coating film at 30 months outdoor exposure, contained 'good' systems (rating $=4)$. Acrylics mainly on substrates with coarse and medium texture were part of this group. The coating film of 'inferior' wood/coating systems (rating > 4), the third group, was obviously damaged starting from the vessel lines and progressing all over the surface. The latter group contained mainly semi-transparent acrylics on coarse wood species, the Whyb stains and opaque Wacr/PU paints. Also wood/coating systems with a rather thin dry coating layer $(\leq 60 \mu \mathrm{m})$ were classified in this group. The Moa_O-WalkWacr systems were classified "inferior" due to small superficial starlike fissures in the topcoat. (Fig. 3 and Table 3)

\section{Factors affecting coating performance}

Coating type, substrate, dry layer thickness and to some extent hiding power of a coating clearly had an impact on the performance of a wood/coating system. Weathering performance was seemingly not significantly influenced by exposure site. Proportional odds logistic regression analysis was performed with three outdoor performance classes as ordinal outcome (inferior < good < excellent) to study the predictive relationships between the above mentioned variables. The model was determined by means of backward and forward regression. No significant effect is found for exposure site. The latter parameter was omitted from the model. Adjusting the main effect model by taking into account the interactions between coating and dry layer, coating and hiding power and dry film thickness and hiding power improved the model $(\mathrm{LR}$ statistic $=30.4, \mathrm{df}=3, \mathrm{p}=0.000)$ yet not all interaction terms have a significant influence. At the 0.05 level only the interaction terms coating*dry layer and dry layer*hiding power are significant (Table 4).

Table 4 Analysis of deviance table indicating the significance level of each factor

\begin{tabular}{lrll}
\hline & LR $\boldsymbol{\chi}^{\mathbf{2}}$ & df & p-value \\
\hline substrate & 8.2705 & 2 & 0.016 \\
dry_layer & 13.6591 & 1 & 0.000 \\
hiding_power & 3.3721 & 1 & 0.066 \\
coating & 2.3382 & 2 & 0.311 \\
coating*dry_layer & 24.5116 & 2 & 0.000 \\
coating*hiding_power & 4.3356 & 2 & 0.114 \\
dry_layer*hiding power & 6.2235 & 1 & 0.013 \\
\hline
\end{tabular}


No evidence was found against the proportional odds assumption $(\mathrm{p}>0.05)$, indicating a good model fit (Bender and Grouven 1997).

The discriminatory power of the model is indicated by the area under the curve (AUC) that plots the fraction of true positives out of the total actual positives versus the fraction of false positives out of the total actual negatives. The predictive power of the model seems adequate as AUC equals 0.79 ( $\mathrm{AUC}=1$ indicates a perfect fit).

Fig. 4 shows the effect of the substrate's texture on the performance of the coating film regardless of the coating type. The graphs indicate that the probability of film degradation increased as the surface texture of the substrate was rougher. The probability that coatings on wood species with fine texture had a better performance at 30 months outdoor weathering is 1.8 (95\% C.I.: $[1.0 ; 3.4])$ times higher than for wood species with coarse texture given that the other variables in the model are held constant. Coatings of a given type with given dry layer thickness on wood species with medium texture have a 0.4 (95\% C.I.: [0.2; 0.8]) times lower probability to perform better at 30 months outdoors than coatings on coarse wood species. This result indicates that the difference between medium and coarse substrates was rather limited.

\section{Substrate effect plot}

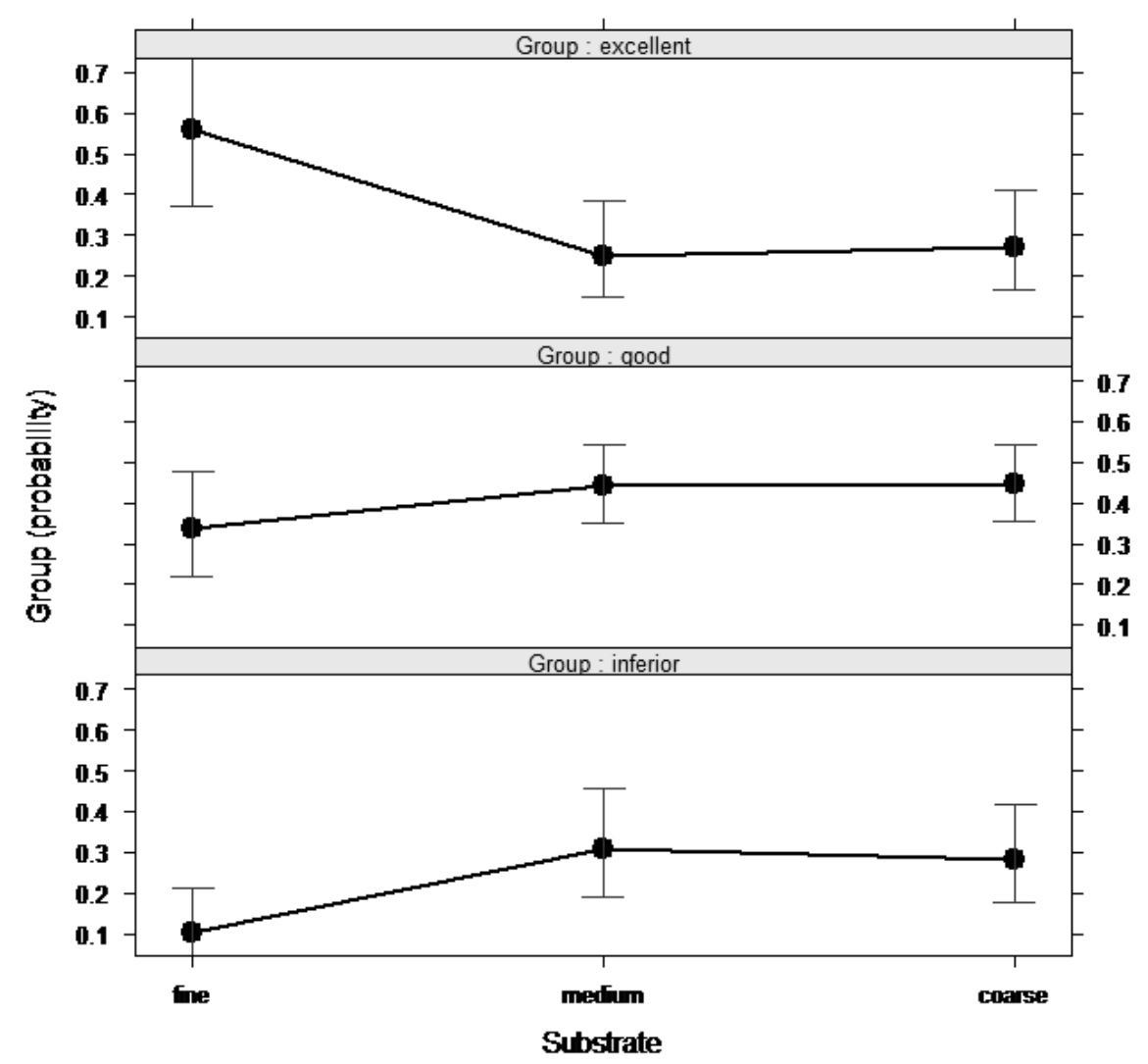

Fig. 4: Effect plot of substrate with indication of $95 \%$ confidence intervals 
Concerning the coating film in general it was seen that the higher the dry layer thickness the better the outdoor performance was at 30 months natural weathering (Fig. 5 and 6). The dry film thickness giving the best possible performance depended on the coating type that was used. Fig. 5 shows that even for a dry coating film of $60 \mu \mathrm{m}$ waterborne acrylics had a higher probability to perform 'good' to 'excellent' than other coating types. However, waterborne acrylics had only a $50 \%$ probability to perform excellent when a dry layer thickness of \pm 135 $\mu \mathrm{m}$ was applied whereas the dry layer thickness of 'Other' and 'WalkWacr' coating types was $\pm 110 \mu \mathrm{m}$. The mild slope of the 'Wacr'-curves indicates that the performance of this coating type was less influenced by the dry layer thickness in contrast to the other coating types tested. 'Other' and 'WalkWacr'coating types differed less. 'Other' coating types had a higher probability to perform better with low dry layer thickness than 'WalkWacr' coating types e.g. $50 \%$ probability to perform inferior for a dry layer thickness of $60 \mu \mathrm{m}$ versus $90 \mu \mathrm{m}$.

\section{Coating*dry_layer effect plot}

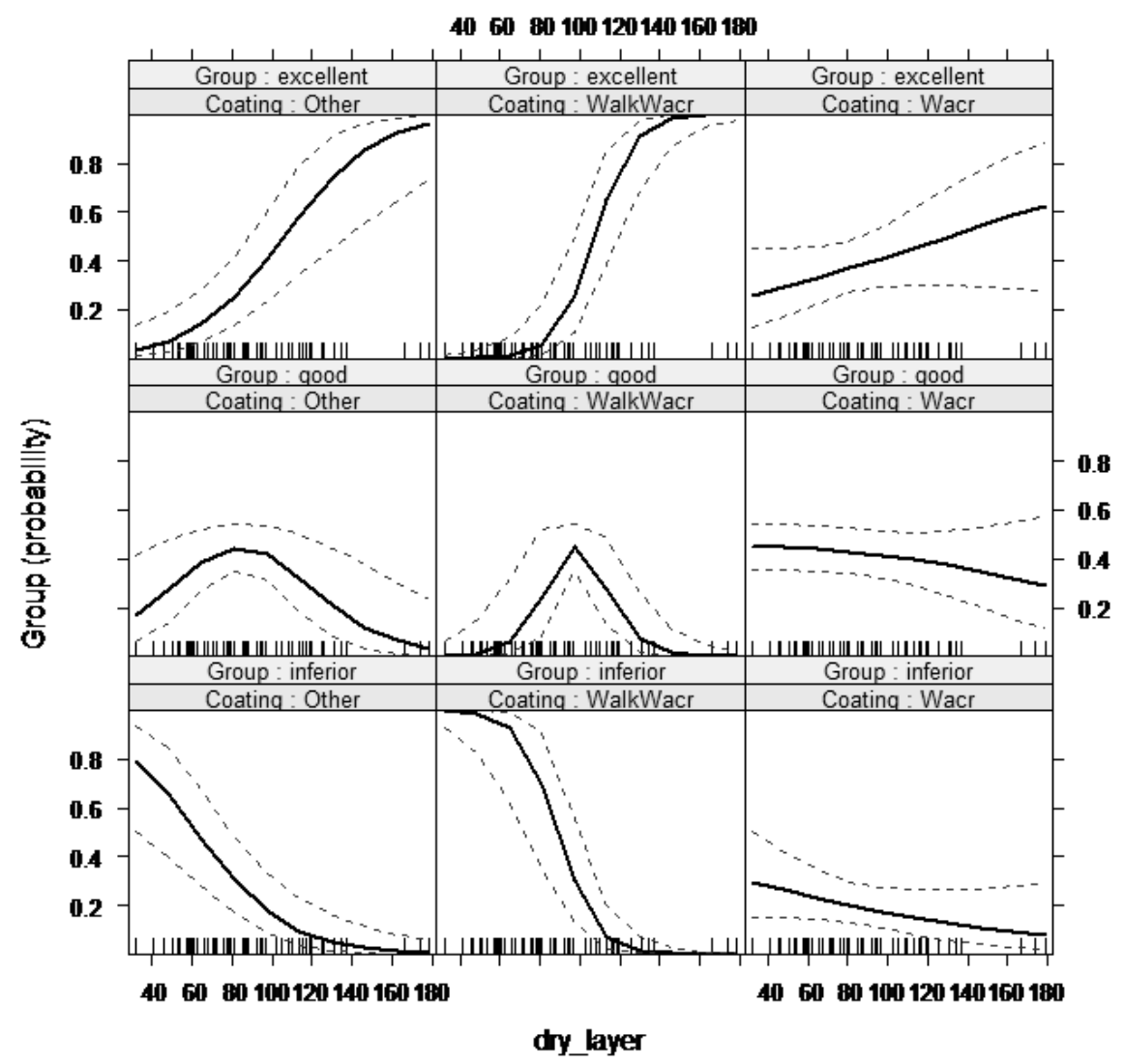

Fig. 5: Effect plot of the interaction between coating type and dry layer thickness with indication of $95 \%$ confidence intervals (dashed line). The inner tick marks on the X-axis represent the measured dry layer thickness ( $1 \mathrm{~m}$ ) of each tested coating. 


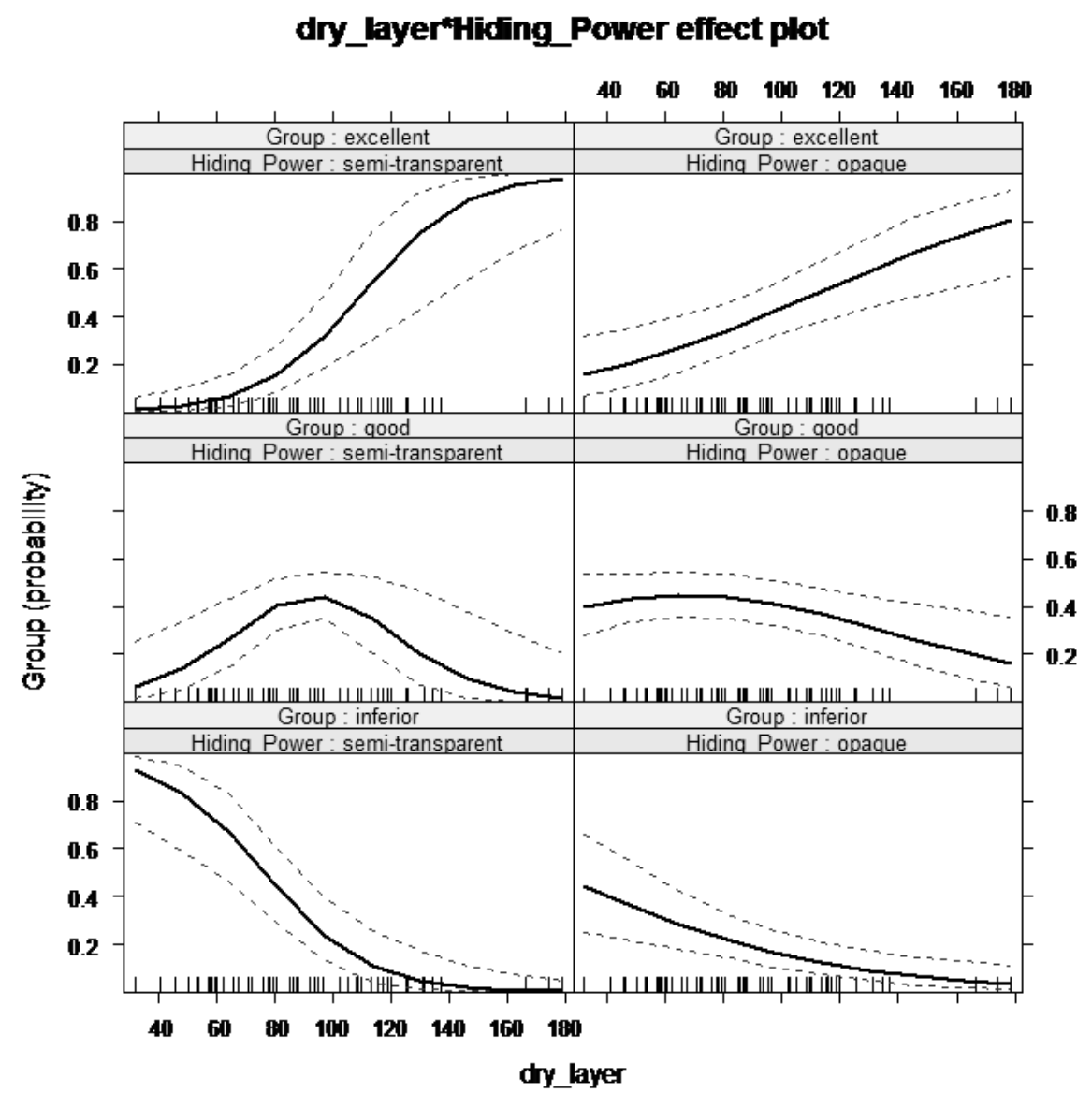

Fig. 6: Effect plot of the interaction between dry layer thickness and hiding power with indication of $95 \%$ confidence intervals (dashed line). The inner tick marks on the X-axis represent the measured dry layer thickness $(\mathrm{lm})$ of each tested coating.

Fig. 6 describes the effect of the interaction of the hiding power and the dry layer thickness on the wood/coating system performance. A similar effect was noticed for the coating*dry layer interaction. The thicker the dry coating layer was, the higher the probability to perform better. The more pronounced curves of semi-transparent stains imply that such wood/coating systems were more sensitive to differences in dry film thickness than opaque paints. For example, opaque paints with a dry layer thickness of $80 \mu \mathrm{m}$ had half the probability to perform 'inferior' than semi-transparent stains with the same coating thickness.

\section{Discussion}

When a coating is properly applied mainly aesthetical changes occur during the first year of outdoor exposure. Loss of gloss and discolouration were the first visible signs of degradation. During the first year of natural weathering wood substrate did not have a significant influence on weathering performance, which is similar to what is generally found by other research teams (Podgorski et al. 1996; Custódio and Eusébio 2006). Some noticeable differences already appeared at 30 months. Mild erosion was then clearly visible by limited superficial damage of the coating layer. Hence, a minimum exposure time of 2.5 years was recommended 
for final performance assessment of coated wooden joinery in natural weathering. In accordance to Van den Bulcke et al. (2006), tropical wood species with large pores, i.e. the coarse textured ones, showed lower performance than the fine textured species. Similar to Roux et al. (1988) damage was mostly localized at the vessel lines. This is most probably a result of inner stresses in the coating near the phase boundary at large vessel lumina. Coating contraction can cause the formation of cavities between coating and cell wall as well as openings within the coating material that covers the pores (Liptáková and Kudela 2002). Once cracks appear in the coating water can easily penetrate the substrate. From this moment on the dimensional stability of the wood species is crucial (Richter et al. 2004). The tropical wood species studied are known for their dimensional stability and thus crack propagation due to swelling and shrinkage of the substrate is limited. Anatomical features of the substrate were clearly of influence on the weathering of coated wood which made a rating as described in Table 2 essential.

Opaque white paints performed somewhat better than semi-transparent mid-oak stains which is obviously related to the UV resistance of the coating (Kropf et al. 1994). However, the differences observed between both coating types were rather subtle as there is a strong significant relationship between dry film thickness and hiding power of a coating system. In general the observed coating performance was mostly good to excellent after five years natural weathering. Waterborne alkyd emulsion primers with acrylic topcoats showed better performance than waterborne acrylics and other coating types studied probably as a result of lower water absorption coefficients (Ekstedt 2003). Dry layer thickness will influence the moisture dynamics too. de Meijer and Militz (2001) proved that a higher film thickness contributes to moisture protection thus inducing better performance. As acrylics are highly permeable a low layer thickness probably provided better evaporation of the absorbed moisture whereas a high layer thickness slows down the drying rate. Hence, wood with a thin acrylic coating film tended to perform better than wood with a thin coating layer of waterborne alkyd primer with acrylics and vice versa wood with a thick acrylic coating layer tended to perform less than wood with a thin film of waterborne alkyd primer and acrylics. Against all expectations the waterborne alkyd primer and acrylic film on moabi performed inferior. The observed defects were typical phenomena of an unbalanced drying process probably as a result of an inadequate application (Tretter 2004).

In line with previous results (Abrahams and Graystone 1996; Creemers et al. 2002) no clear relation was found between exposure site and weathering behaviour if the performance of sill 
and corner joints were not taken into account. The assessment of the latter window parts requires other criteria focusing on damage related to moisture dynamics.

\section{Conclusion}

Wood coating research almost exclusively focuses on softwood as substrate. EN927 also prescribes softwood for testing wood coatings designed for tropical hardwood despite the fact that softwood and tropical hardwood have a different weathering behaviour. An adapted rating scale was introduced, taking into account the differences in anatomical characteristics between hard- and softwood. By applying a set of statistical methods, the weathering performance of different wood/coating systems was thoroughly analysed.

Although most waterborne coatings performed well, even after five years outdoors, the first differences in performance of coated surfaces in vertical exposure could only be noticed after a minimum required exposure time of 2.5 years.

In general, the degradation rate of coarse textured hardwood species was the highest. No significant difference in degradation rate was found between medium and coarse textured species. The significant influence of substrate texture on the coating performance stressed the need to evaluate the wood/coating system in total.

Best performance was recorded for waterborne alkyd primers with a waterborne acrylic topcoat. Coating performance enhanced with increasing dry layer thickness but not in the same way for different coating types. Probably this could be explained by the differences in moisture behaviour between the different coating types. Nevertheless, thin coating layers tended to degrade rather quickly as UV resistance is diminished which is evident for semitransparent stains. Dry layer thickness also affected the significance of hiding power on the performance of the wood/coating system. No significant influence of exposure site was found. In this paper the authors tried to define and to understand the outdoor weathering performance parameters of interest for finished exterior wooden joinery. Increasing the knowledge of the weathering behaviour of waterborne coatings on different substrates improves the service life prediction of coated joinery for exterior use.

\section{Acknowledgements}

The research was performed within the framework of the Belgian national research project 'Optiwoodcoat'. The authors would like to thank the agency for Innovation by Science and Technology (IWT) for its financial support. 


\section{References}

Abrahams IL, Graystone JA (1996) Natural weathering of exterior wood coatings: a comparison of performance at five European sites. Proceedings XXII FATIPEC Congress, Brussels, Belgium

Boxall J, Carey JK, Miller ER (1992) The effectiveness of end-grain sealers in improving paint performance on softwood joinery - Part 3: Influence of coating type and wood species on moisture content and fungal colonisation. Holz Roh Werkst 50: 227-232

Bender R, Grouven U (1997) Ordinal logistic regression in medical research. J Roy Coll Phys Lond 31(5): 546551

Bennett KD (1996) Determination of the number of zones in a biostratigraphical sequence. New Phytol 132: $155-170$

Birks HJB, Gordon AD (1985) Numerical methods in Quaternary pollen analysis. Academic Press, London Brant Rollin (1990) Assessing Proportionality in the Proportional Odds Model for Ordinal Logistic Regression. Biometrics Vol. 46 (4): 1171-1178

Creemers J, de Meijer M, Zimmerman T, Sell J (2002) Influence of climatic factors on the weathering of coated wood. Holz Roh Werkst 60: 411-420

CEN/TC139 (2013) Paints and varnishes - Coating materials and coating systems for exterior wood - Part 1: Classification and selection. EN927-1.

CEN/TC139 (2006) Paints and varnishes - Coating materials and coating systems for exterior wood. Part 3: Natural weathering test. EN 927-3

CIRAD (2012) TROPIX 7 $7^{\circledR}$. http://tropix.cirad.fr. Accessed October 2012

Custódio JEP, Eusébio MI (2006) Waterborne acrylic varnishes durability on wood surfaces for exterior exposure. Prog Org Coat 56: 59-67

de Meijer M, Nienhuis J (2009) Influence of internal stress and extensibility on the exterior durability of wood coatings. Prog Org Coat 65: 498-503

de Meijer M, Militz H (2001) Moisture transport in coated wood. Part 2: Influence of coating type, film thickness, wood species, temperature and moisture gradient on kinetics of sorption and dimensional change.

Holz Roh Werkst 58: 467-475 
Ekstedt J (2003). Influence of coating system composition on moisture dynamic performance of coated wood. J

Coating Technol 75: 27-37

Grimm EC (1987) CONISS: a FORTRAN 77 program for stratigraphically constrained cluster analysis by the methods of incremental sum of squares. Comput Geosc-UK 13: 13-35

Grüll G, Truskaller M, Podgorski L, Bollmus S, De Windt I, and Suttie E. (2013) Moisture conditions in coated wood panels during 24 months natural weathering at five sites in Europe Wood Mater Sci Eng 8(12): 95-110

Kropf FW, Sell J, Feist WC (1994) Comparative weathering tests of North American and European exterior wood finishes. Forest Prod J 44(10): 33-41

Liptáková E and Kudela J (2002) Study of the system wood-coating material part 2: Wood-solid coating material. Holzforschung 56 (5): 547-557

Nejad M, Cooper P (2011) Performance of semitransparent stains on preservative-treated wood. J Coating Technol 8(4): 449-458

Nicholson JW (1993) Waterborne Coatings. OCCA Student Monograph No. 8

Overbeek A (2010) Polymer heterogeneity in waterborne coatings. J Coating Technol 7(1): 1-21

Perera DY (1996) On adhesion and stress in organic coatings. Prog Org Coat 28: 21-23

Petersen AK, Solberg B (2005) Environmental and economic impacts of substitution between wood products and alternative materials: a review of micro-level analyses from Norway and Sweden. Forest Policy Econ 7: 249-259

Podgorski L, Merlin A, Deglise X (1996) Analysis of the natural and artificial weathering of a wood coating by measurement of glass transition temperature. Holzforschung 50: 282-287

R Development Core Team (2010) R: A language and environment for statistical computing. Vienna, Austria: R Foundation for Statistical Computing. Retrieved from http://www.R-project.org.

Richter K, Feist WC, Knaebe M (1995) The effect of surface roughness on the performance of finishes. Part 1. Roughness characterization and stain performance. Forest Prod J 45 (7/8): .91-97

Richter HG, Schwab E, von Arps-Aubert T, Nock H-P (2004) Quality assessment of laminated window scantlings from mixed tropical hardwoods after long-term exposure to weathering. J Trop For Sci 16(3): 350-356

Rijckaert V, Stevens M, Van Acker J, de Meijer M, Militz H (2001). Quantitative assessment of the penetration of water-borne and solvent-borne wood coatings in Scots pine sapwood. Holz Roh Werkst 59(4): 278-287 
Roux ML, Wozniak E, Miller ER, Boxall J, Böttcher P, Kropf F, Sell J (1988) Natural weathering of various surface-coatings on 5 species at 4 European sites. Holz Roh Werkst 46(5): 165 -170

Salazar J, Sowlati T (2008) A review of life cycle assessment of windows. Forest Prod J 58(10): 91-96

Tretter A (2004) Holzlackschäden - Beschichtungsmängel an Fenstern: Erkennen, Vermeiden, Sanieren. DRWVerlag. Leinfelden-Echterdingen. 125p.

Van Acker J, Stevens M, Nys M (1992) Xenon simulation of natural weathering of external joinery preserving Finishing systems. International Research Group on Wood Protection, 23rd Annual meeting, Harrogate, UK.

IRG 92-2412

Van den Bulcke J, Rijckaert V, Van Acker J, Stevens M (2003) Quantitative measurement of the penetration of water-borne coatings in wood with confocal lasermicroscopy and image analysis. Holz Roh Werkst 61: 304-310

Van den Bulcke J, Rijckaert V, Van Acker J, Stevens M (2006) Adhesion and weathering performance of waterborne coatings applied to different temperate and tropical wood species. J Coating Technol 3(3): 185 -191

Verband der Fenster- und Fassadenhersteller (2011) European window market study. Frankfurt, Germany.

Williams RS, Jourdain C, Daisey GI, Springate RW (2000) Wood properties affecting service life. J Coating Technol 72: 35-42 